\title{
Inhibitory Actions of Captopril on Norepinephrine Release from Adrenergic Nerve Endings in Spontaneously Hypertensive Rats
}

\author{
Kazushi Tsuda, M.D., Seiko Tsuda, M.D., Masako Ura, M.D., \\ Hiroki Shima, M.D., Ichiro Nishio, M.D., \\ and Yoshiaki Masuyama, M.D.
}

\begin{abstract}
SUMMARY
The purpose of the present study was to investigate the mechanisms of the hypotensive actions of an angiotensin converting enzyme inhibitor (captopril) in hypertension. In perfused mesenteric vasculatures from spontaneously hypertensive rats (SHR, Okamoto and Aoki strain, 10-13 weeks of age) and age-matched normotensive Wistar Kyoto rats (WKY), the effects of captopril on vascular responsiveness and norepinephrine release from the adrenergic nerve endings were examined. The vasoconstrictor responses and norepinephrine release during the electrical nerve stimulation were significantly enhanced in SHR compared to those in age-matched WKY. Captopril reduced both vasoconstrictor responses and norepinephrine release during the electrical nerve stimulation, dosedependently. These inhibitory effects of captopril were significantly greater in SHR than in WKY.

The results demonstrate that captopril affects presynaptic sites on the resistance vessels and causes a decrease in electrically-stimulated norepinephrine release from the adrenergic nerve endings. The marked reduction of both pressor responses and norepinephrine release by captopril in SHR suggests an enhanced renin-angiotensin system in the vascular walls of hypertension.
\end{abstract}

\section{Additional Indexing Words:}

Angiotensin converting enzyme inhibitor Captopril Norepinephrine release Sympathetic nervous system Vascular responsiveness Mesenteric vasculature Spontaneously hypertensive rats

\footnotetext{
YAPTOPRIL, an orally active inhibitor of the angiotensin converting 1 enzyme, has an effective antihypertensive action in hypertensive animals and human hypertensive subjects. ${ }^{1,2)}$ This hypotensive action of captopril has been believed to depend on a reduction of the circulating angiotensin II level in the blood. However, there is some evidence that the eff-

From the Division of Cardiology, Department of Medicine, Wakayama Medical College, Wakayama, Japan.

Received for publication December 27, 1986.
}

Accepted September 16, 1987. 
cacy of captopril is found not only in high renin models but also in normal renin models of hypertension. ${ }^{3)}$ Recently, it has been suggested that the renin-angiotensin system exists in a variety of tissues, such as brain, adrenal medulla and vascular tissues, ${ }^{4), 5}$ and that locally generated angiotensin II might play an important role in the development of hypertension. Schacht ${ }^{6}$ ) reported that captopril acted on the central nervous system, which might be explained by a decrease in the central sympathetic nerve activity. Collis et $\mathrm{al}^{\text {7) }}$ observed that captopril could depress the sympathetic vasoconstriction in rat mesenteric arteries. It was also demonstrated that captopril decreased the pressor responses evoked by electrical stimulation, suggesting that the drug could interfere with peripheral adrenergic neuro-effector mechanisms. ${ }^{8)}$ The present study was performed to investigate whether captopril has an inhibitory effect on adrenergic transmission in the resistance vessels of hypertensive rats.

\section{Materials and Methods}

Male spontaneously hypertensive rats (SHR, Okamoto and Aoki strain, 10-13 weeks old) were studied in comparison with age- and sex-matched Wistar Kyoto rats (WKY) from Charles River Inc. (Japan). The systolic blood pressures, measured by the tail-cuff method (programmed electro-

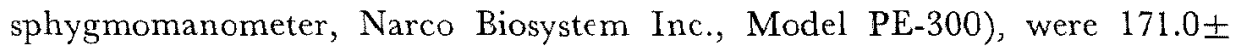
$5.6 \mathrm{mmHg}$ (mean $\pm \mathrm{SEM}, \mathrm{n}=5)$ in SHR and $121.2 \pm 9.7 \mathrm{mmHg}(\mathrm{n}=6)$ in WKY. Rats were anesthetized with pentobarbital $(40 \mathrm{mg} / \mathrm{kg}$, intraperitoneal injection), and perfused mesenteric vasculatures were prepared according to the method of Castellucci et al. ${ }^{9}$ ( The superior mesenteric artery was perfused through a cannula inserted at its origin from the aorta. In each preparation, only four main branches from the superior mesenteric artery trunk were used. All other branches were tied off. The isolated preparation was placed in a chamber maintained at $37^{\circ} \mathrm{C}$ and gently laid on gauze to avoid any traction on the cannulated artery. The preparation was perfused with a modified Ringer-Locke solution (mmol/1: $\mathrm{NaCl} 120.7, \mathrm{KCl} 5.9, \mathrm{CaCl}_{2} 2.5$, $\mathrm{MgSO}_{4}$ 1.3, $\mathrm{NaHCO}_{3}$ 15.5, $\mathrm{NaH}_{2} \mathrm{PO}_{4} 1.2$ and glucose 11.5, $\mathrm{pH} 7.4,37^{\circ} \mathrm{C}$ ), and bubbled with a $95 \% \mathrm{O}_{2}$ and $5 \% \mathrm{GO}_{2}$ mixture. A constant flow rate was maintained with a peristaltic pump (Harvard apparatus, Model 1200) at $0.8 \mathrm{~m} / / \mathrm{min}$. Changes in the perfusion pressure were monitored with a pressure transducer connected to a polygraph (Nihon Kohden, Model GP-620G).

Periarterial nerve stimulation was performed with bipolar platinum electrodes around the proximal end of the mesenteric artery. The stimulation was applied at a supramaximal voltage $(40 \mathrm{~V})$, with rectangular pulses of $5 \mathrm{msec}$ duration for $1 \mathrm{~min}$ at 5 and $15 \mathrm{~Hz}$ (electrical stimulator: Nihon 
Kohden, Model SEN-3201). Pressor responses to the electrical nerve stimulation were determined as increases in the perfusion pressure. After perfusion of the mesenteric vascular beds was initiated, the basal perfusion pressure was allowed to stabilize for $30 \mathrm{~min}$ prior to onset of the experimental manipulations.

Measurement of norepinephrine release during nerve stimulation in mesenteric vasculatures:

For the measurement of norepinephrine release from sympathetic nerve endings, the perfusate through the mesenteric preparation was collected in a tube containing EGTA $(90 \mathrm{mg} / \mathrm{ml})$ and glutathione $(60 \mathrm{mg} / \mathrm{ml})$ in $20 \mu l$ of the perfusate. The collecting periods were $3 \mathrm{~min}$ before nerve stimulation (A) and $2 \mathrm{~min}$ after cessation of $1 \mathrm{~min}$-stimulation (total $3 \mathrm{~min}$ ) (B). The norepinephrine release evoked by the electrical nerve stimulation was defined as the norepinephrine overflow, which was the difference of the norepinephrine contents between (A) and (B), and was normalized per gram of wet tissue weight for each preparation.

Norepinephrinc in the perfusate was adsorbed on alumina, extracted in $200 \mu l$ of perchloric acid $(0.1 \mathrm{~mol} / 1)$, and assayed by high performance liquid chromatography ${ }^{10), 11)}$ with an electrochemical detector (Bioanalytical system, Model LG-4A, carbon electrode, $700 \mathrm{mV}$ ). The HPLC unit was equipped with a delivery system (Waters Assoc., Model 510 , flow rate $1.0 \mathrm{~m} /$ / min), an automatic injector (Waters Assoc., Model 710B, injected volume $100 \mu l)$ and Biophase ODS $5 \mu \mathrm{m}$ column. The solvent for the separation of norepinephrine was $0.1 \mathrm{~mol} / 1$ of monochloric acid with $2 \mathrm{mmol} / 1$ of EDTA, $300 \mathrm{mg} / 1$ of sodium octyl sulfate and $9 \%(\mathrm{v} / \mathrm{v})$ of acetonitrile $(\mathrm{pH} 3.02$ at room temperature).

In the first series of experiments, the pressor responses and norepinephrine release during the electrical nerve stimulation were examined in SHR and WKY. Then, captopril was added to the perfusion medium to achieve final concentrations of $5.0 \times 10^{-6} \mathrm{~mol} / 1$ to $5.0 \times 10^{-5} \mathrm{~mol} / 1$. After drug administration, a 9 min-period elapsed before the next electrical stimulation. For each preparation, the results were evaluated by comparing the responses before (control) and during the infusion of captopril (experimental), and then expressed as percentage ratios of the control response for each experiment. Thus, a value greater than $100 \%$ would indicate enhancement and that lcss than $100 \%$ would represent inhibition. ${ }^{12}$

Values are expressed as mean \pm SEM. Statistical significances were determined by Student's t-test, Mann-Whitney U-test and 2 way-analysis of variance (ANOVA). ${ }^{13)}$ The differences of $p<0.05$ were considered signifi- 
cant.

Captopril was kindly donated by Sankyo Co., Ltd. (Tokyo, Japan).

\section{RESULTS}

The pressor responses and norepinephrine overflow during the electrical nerve stimulation were completely blocked when guanethidine was added into the perfusion medium, reproducing a previous result. ${ }^{14)}$ This indicates that the effects of periarterial electrical stimulation are neurally mediated. The pressor responses and norepinephrine overflow during the nerve stimulation did not significantly change for at least 7 repeated stimuli in the same preparation, documenting reproducibility and stability. ${ }^{14)}$

The basal perfusion pressure and norepinephrine content in the perfusate during the unstimulated period (spontaneous norepinephrine efflux from the vascular beds) were not significantly different between SHR and

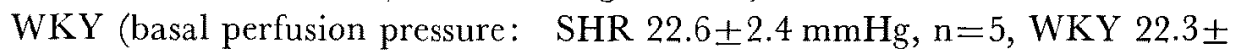
$2.2 \mathrm{mmHg}, \mathrm{n}=6$; norepinephrine content in the perfusate during unstimulated $3 \mathrm{~min}$ : SHR $0.32 \pm 0.06 \mathrm{ng} / \mathrm{g}$ of wet tissue weight, $\mathrm{n}=5$, WKY $0.30 \pm$ $0.04 \mathrm{ng} / \mathrm{g}$ of wet tissue weight, $\mathrm{n}=5$ ). As shown in Fig. 1, the pressor re-

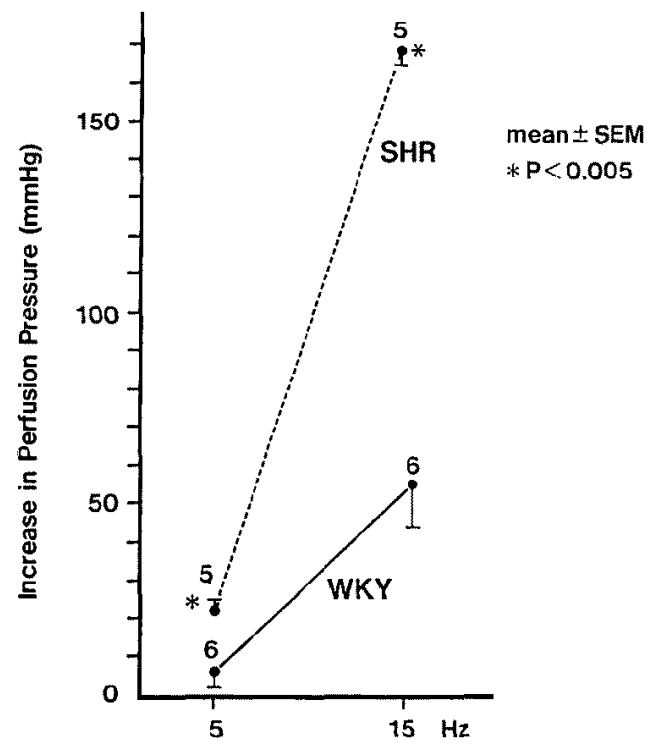

Fig. 1. Pressor responses to electrical nerve stimulation in the mesenteric vasculature preparations from SHR and age-matched WKY. Electrical nerve stimulation was performed at 5 and $15 \mathrm{~Hz}$ frequencies (supramaximal voltage $40 \mathrm{~V}, 5 \mathrm{msec}$ duration of rectangular pulscs for $1 \mathrm{~min}$ ). Pressor rcsponses arc represented as increases in the perfusion pressures of the preparations. 


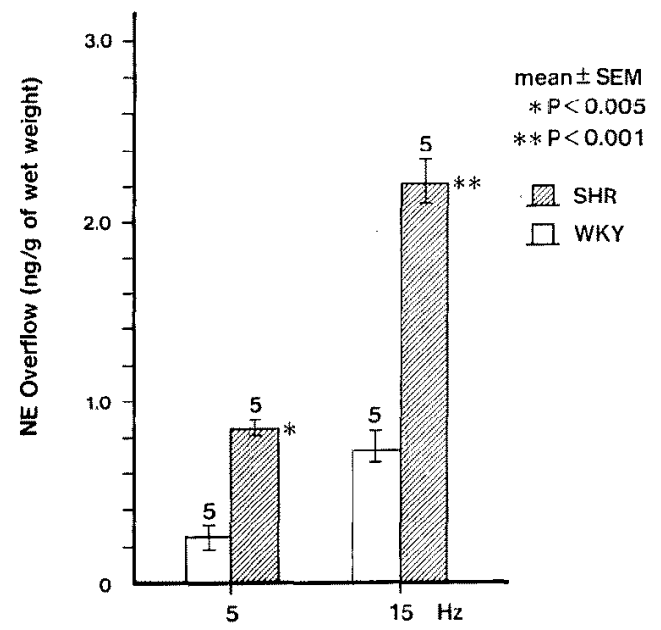

Fig. 2. Norepinephrine overflow during electrical nerve stimulation in the mesenteric vascular preparations from SHR and WKY. Norepinephrine overflow was expressed as nanogram/gram of wet tissue weight of each preparation.

sponses to the electrical nerve stimulation were significantly greater in SHR than in WKY (5 Hz: SHR $24.5 \pm 1.3 \mathrm{mmHg}, \mathrm{n}=5$, WKY $5.7 \pm 0.3 \mathrm{mmHg}$, $\mathrm{n}=6, \mathrm{p}<0.005,15 \mathrm{~Hz}$ : SHR $169.5 \pm 3.5 \mathrm{mmHg}, \mathrm{n}=5$, WKY $56.5 \pm 10.7$ $\mathrm{mmHg}, \mathrm{n}=6, \mathrm{p}<0.005)$. The norepinephrine overflow during the electrical nerve stimulation was also enhanced in SHR (Fig. 2; $5 \mathrm{~Hz}$ : SHR 0.84 $0.07 \mathrm{ng} / \mathrm{g}$ of wet tissue wcight, $\mathrm{n}=5$, WKY $0.23 \pm 0.08 \mathrm{ng} / \mathrm{g}$ of wet tissue weight, $\mathrm{n}=5, \mathrm{p}<0.005,15 \mathrm{~Hz}$ : SHR $2.21 \pm 0.14 \mathrm{ng} / \mathrm{g}$ of wet tissue weight, $\mathrm{n}=5$, WKY $0.74 \pm 0.12 \mathrm{ng} / \mathrm{g}$ of wet tissue weight, $\mathrm{n}=5, \mathrm{p}<0.001)$.

\section{Effects of captopril on pressor responses and nortpinephrine release in SHR:}

When captopril $\left(5.0 \times 10^{-6} \mathrm{~mol} / 1-5.0 \times 10^{-5} \mathrm{~mol} / 1\right)$ was added into the pcrfusion medium, the basal perfusion pressurc did not change in any preparations. Figure 3 and Table I show the effects of captopril on the pressor responses evoked by the electrical nerve stimulation. Captopril dose-dependently reduced the pressor responses both in SHR and WKY, and the suppressive magnitudes were significantly greater in SHR than in WKY. Further, Table I documents changes in the norepinephrine release in the presence of captopril in SHR and WKY. The norepinephrine overflow during the electrical nerve stimulation was also inhibited by captopril. This neurosuppressive action was more marked in SHR than in WKY: 

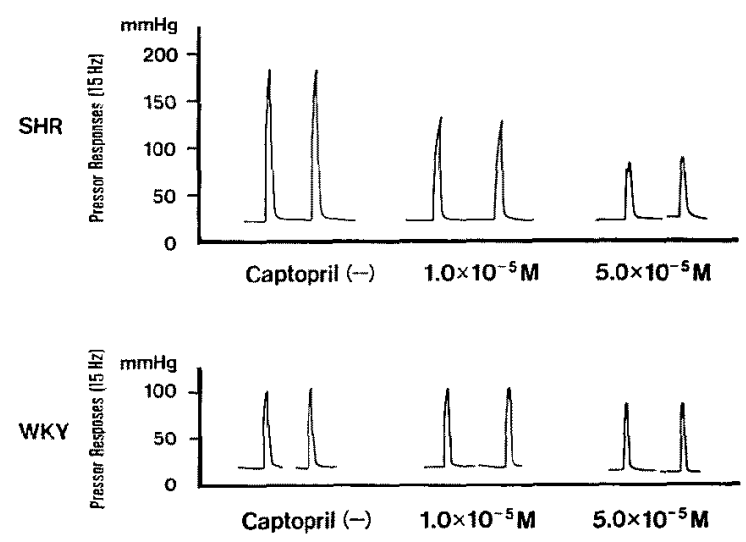

Fig. 3. Typical changes in the stimulation-evoked pressor responses in SHR and WKY when captopril was added into the perfusion medium (SHR: upper half, WKY: lower haif).

Table I. Comparison of the Effects of Captopril on Electrically-induced Pressor Responses $(15 \mathrm{~Hz})$ and Norepinephrine (NE) Overfow $(5,15 \mathrm{~Hz})$ in the Mesenteric Vasculatures from SHR (10-13 weeks old) and Age-matched Normotensive WKY

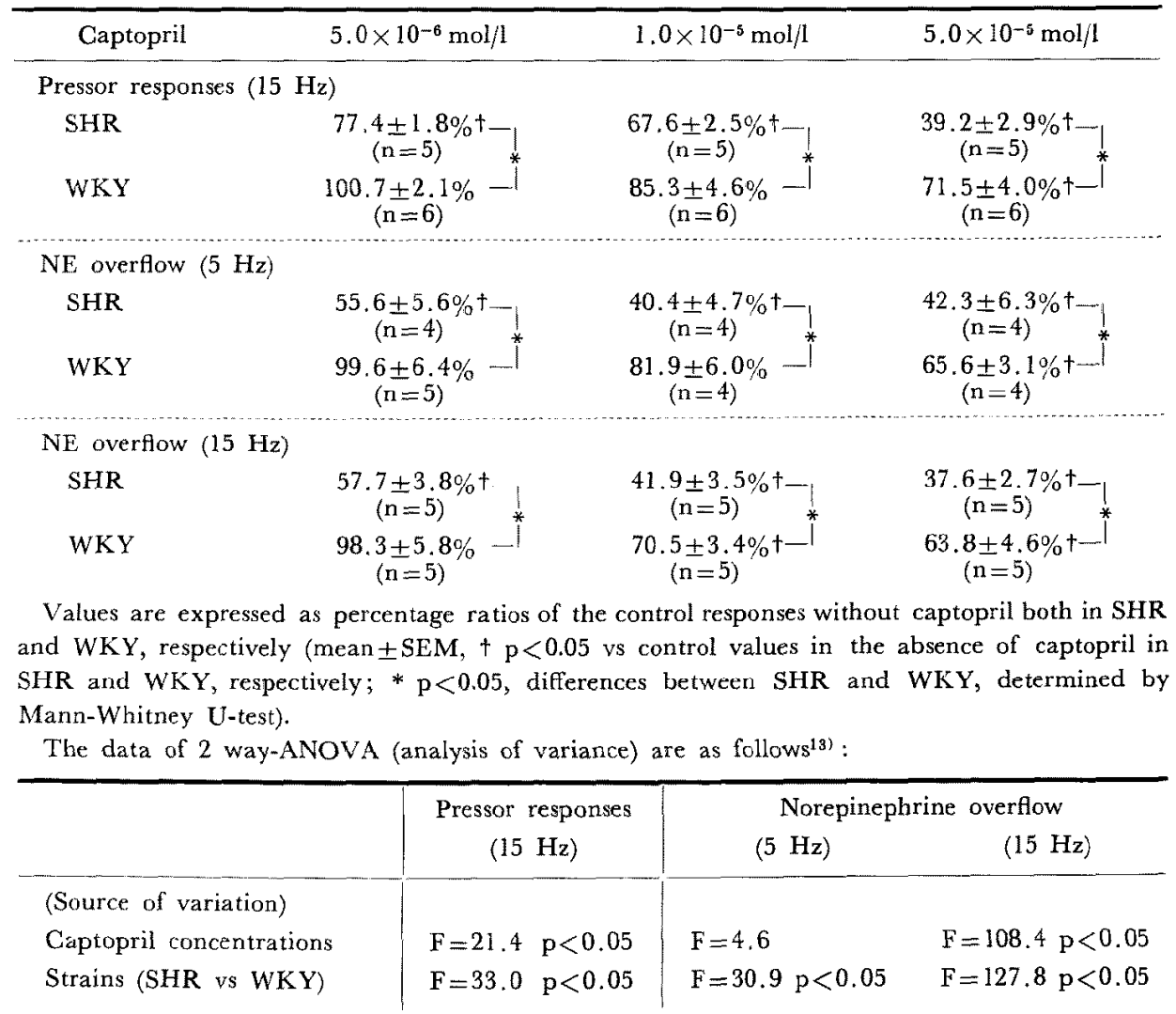




\section{Discussion}

The present study demonstrated that captopril has a presynaptic effect on sympathetic vascular transmission, resulting in a decrease in the stimulation-induced norepinephrine release from the adrenergic nerve endings. It was also observed that these inhibitory actions were more prominent in SHR than in WKY. These results confirm the hypothesis that the hypotensive mechanisms of captopril are related to inhibition of the sympathetic nerve activity. ${ }^{7), 8}$ Captopril is a potent inhibitor of angiotensin converting enzyme. Thus, it is likely that the sympathetic inhibitory action of captopril might be due to the suppression of angiotensin II formation in the vascular beds. It has been suggested that the renin-angiotensin system is present in a variety of tissues, including vascular walls, ${ }^{4), 5)}$ and that locally generated angiotensin II might facilitate the adrenergic transmission by enhancing the norepinephrine release from nerve endings. ${ }^{15 l}$ Garst et al ${ }^{16)}$ reported that the vascular renin level was elevated in SHR whereas plasma renin activity was not high; this state could produce greater angiotensin II formation in the blood vessel walls of SHR. It is now clearly established that captopril is an effective antihypertensive drug in SHR but not in normotensive WKY, although plasma renin activity is not different between the 2 groups. ${ }^{1,16), 171}$ Therefore, the efficacy of captopril in SHR may reflect an action of captopril on the enhanced renin-angiotensin system in the vascular beds. This action would decrease angiotensin II formation, a concomitant reduction of norepinephrine release and an inhibition of pressor responses.

Collis et $\mathrm{al}^{71}$ reported that captopril antagonized the vasoconstrictor responses evoked by sympathetic nerve stimulation. Antonaccio et al ${ }^{18)}$ found that oral administration of captopril into conscious SHR caused significant reduction in the pressor responses to sympathetic nerve stimulation, but had no effect on the positive chronotropic responses evoked by exogenous angiotensin II or norcpinephrine in the same animals. These suggest that captopril presynaptically inhibits norepinephrine release in SHR. This study with direct measurement of endogenous norepinephrine release observed that captopril markedly reduced norepinephrine release during the electrical nerve stimulation at both low $(5 \mathrm{~Hz})$ and high $(15 \mathrm{~Hz})$ frequencies in SHR.

These neurosuppressive effects of captopril may reflect a direct action on the sympathetic neurons. This possibility cannot be excluded. However, it has been reported that the blood captopril concentration peaks at an order of $10^{-6} \mathrm{~mol} / \mathrm{l}$ when $50 \mathrm{mg}$ of the drug is orally administered to essential hypertensive patients. ${ }^{19}$ Further, our data showed that a low concentration of captopril $\left(5.0 \times 10^{-6} \mathrm{~mol} / \mathrm{l}\right)$ significantly affected the norepinephrine release in 
SHR but not in WKY (Table I). This similarity in effective doses suggests a similar basis for these effects, which may reflect differences in the vascular renin-angiotensin system between SHR and WKY.

Antonaccio and Kerwin ${ }^{201}$ reported that the effects of captopril on blood pressure were not prominent in DOCA-salt hypertension with very low plasma and vascular renin activities. This finding also provides evidence that the hypotensive action of captopril depends upon its accessibility to the vascular renin-angiotensin system. In summary, the effects of captopril on norepinephrine release from the sympathetic nerve endings are consistent with the hypothesis that the antihypertensive action of captopril might be due to interference with the peripheral adrenergic neuro-effector mechanisms in the resistance vessels.

\section{Acknowledgments}

This study was supported in part by Grants-in-Aids for Scientific Research (60570404, 60440049, 62304041) from the Ministry of Education, Science and Culture (Japan), and by the Nanki Scholarship Fund.

\section{REFERENCES}

1. Antonaccio MJ, Rubin B, Horowitz B: Effects of captopril in animal models of hypertension. Clin Exp Hypertens 2: 613, 1980

2. Ciase DB, Atlas SA, Laragh JH, Sealey JE, Sullivan PA, McKinstry DN: Clinical experience with blockade of the renin-angiotensin-aldosterone system by an oral converting enzyme inhibitor (SQ 14 225, captopril) in hypertensive patients. Progr Cardiovasc Dis 21 : 195, 1978

3. Cushman DW, Ondetti MA, Cheung HS, Antonaccio MJ, Murthy VS, Rubin B: Inhibitors of angiotensin converting enzyme. in The Renin Angiotensin System, ed by Johnson JA, Anderson RA, Plenum Publishing Corporation, New York, p 199-225, 1980

4. Re R, Fallon JT, Dzau V, Quay SC, Harber E: Renin synthesis by canine aortic smooth muscle cells in culture. Life Sci 30: 99, 1982

5. Ganten D, Schelling $\mathbf{P}$, Vecsei $\mathbf{P}$, Ganten U: Iso-renin of extrarenal origin: the tissue angiotensinogenase system. Am J Med 60: 760, 1976

6. Schacht U: Effects of angiotensin II and ACE inhibitors on electrically stimulated noradrenaline release from superfused rat brain slices. Clin Exp Hypertens A6: 1847, 1984

7. Collis $M G$, Keddie JR: Captopril attenuates adrenergic vasoconstriction in rat mesenteric arteries by angiotensin-dependent and independent mechanisms. Clin Sci 61: 281, 1981

8. Clough DP, Collis MG, Hatton R, Keddie JR: Effect of angiotensin converting enzyme inhibitor on neurogenic vasoconstriction in the rat. Blood Vessels 17: 147, 1980

9. Castellucci A, Bacciarelli C, Boni P, Fedi M: The rat mesenteric artery-intestinal loop preparation. Arzneim Forsch Drug Res 31: 54, 1981

10. Hjemdahi P, Daleskog M, Kahan T: Determination of plasma catecholamines by high performance liquid chromatography with electrochemical detector. Life Sci 25: 131, 1979

11. Hallman H, Farnebo LO, Hamberger B, Jonsson G: A sensitive method for the determination of plasma catecholamines using liquid chromatography with electrochemical detection. Life Sci 23: 1049, 1978

12. Campbell WB, Jackson ED: Modulation of adrenergic transmission by angiotensins in the 
perfused rat mesentery. Am J Physiol 236: H211, 1979

13. Murphy EA: Analysis of variance. in Biostatistics in Medicine, ed by Murphy EA, The Johns Hopkins University Press, p 137-174, 1982

14. Tsuda K, Kuchii M, Kusuyama Y, Hano T, Nishio I, Masuyama $Y$ : Neurotransmitter release and vascular reactivity in spontaneously hypertensive rats. Jpn Circ J 48: 1263, 1984

15. Toda $\mathrm{N}$, Miyazaki M, Okamura $\mathrm{T}$ : Vascular neuroeffector function in two-kidney, oneclip hypertensive dogs. J Hypertens 3: 503, 1985

16. Garst J, Koletsky $\mathrm{S}$, Wisenbaugh PE, Haddy M, Mathews D: Arterial wall renin and renal venous renin in the hypertensive rat. Clin Sci 56: 41,1979

17. Asaad MM, Antonaccio MJ : Vascular wall renin in spontaneously hypertensive rats. Hypertension 4: 487, 1980

18. Antonaccio MJ, Kerwin L: Pre- and postjunctional inhibition of vascular sympathetic function by captopril in SHR: Implication of vascular angiotensin II in hypertension and antihypertensive actions of captopril. Hypertension 3 (suppl I): 54, 1981

19. Shimada K, Tanaka M, Nambara T, Imai X, Abe K, Yoshinaga K: Determination of captopril in human blood by high-performance liquid chromatography with electrochemical detection. J Chromatogr 227: 445, 1982

20. Antonaccio MJ, Kerwin L: Evidence for prejunctional inhibition of norepinephrine release by captopril in spontaneously hypertensive rats. Eur J Pharmacol 68: 209, 1980 